\title{
"Compañeros en una misión de reconciliación y justicia"*
}

\author{
Juan Hernández Pico, S. J. \\ Departamento de Teología \\ San Salvador, El Salvador
}

\section{Introducción: ¿Cambia la misión o se actualiza?}

¿Se ha desviado la Congregación General (CG) 36 de la Compañía de Jesús (2015-2016) del énfasis que desde la CG 32 (1974-1975) había puesto en la opción de la lucha por la justicia'? Esta pregunta surge, inevitablemente, al leer el título del primero de los dos únicos decretos de dicha congregación ${ }^{2}$ y al compararlo con la "nueva misión", promulgada por la CG 32. Y también surge en los jesuitas y sus colaboradores, que consideraron y aún consideran oportuno y audaz el modo como la cuestión fue propuesta, discutida, escrita y aprobada, bajo la inspiración del P. Arrupe 3: "La lucha por la fe y la lucha por la justicia que la misma fe exige" (CG 32, D 2) y "Nuestra Misión hoy: servicio de la fe y promoción de la justicia" (CG 32, D 4).

* Comentario al Decreto 1 de la Congregación General 36 de la Compañía de Jesús.

1. CG 32, D 2, 2 .

2. El Decreto 2 se titula "Un gobierno renovado para una misión renovada" (los énfasis son míos). Permítaseme anotar que según el diccionario de la Real Academia Española, algo "renovado" puede ser desde algo "innovado, reformado, cambiado o incluso reemplazado o sustituido", hasta algo "actualizado, restaurado, mejorado, reanudado, refrescado, vivificado o regenerado". Así, pues, esto supone la auténtica transformación de la misión de la Compañía de Jesús o esa misma misión, según los acentos de las congregaciones 32-35. Más adelante, podremos decidirnos por una de estas posibilidades.

3. Con la cooperación de varios jesuitas: Jean-Yves Calvez (francés); Horacio de la Costa (filipino); Carlo María Martini (italiano), luego arzobispo de Milán; Bartolomeo Sorge (italiano), director de La Civiltà Cattolica; Alfonso Álvarez Bolado (español); Enrique Gutiérrez Martín del Campo y Javier Scheifler (mexicanos); Parmananda Divarkar (indio); y Vincent O'Keefe (estadounidense). 
Parece evidente que la pregunta la suscita el título del decreto, al unir "reconciliación" y "justicia" con la máxima conjunción copulativa: "Compañeros en una misión de reconciliación y de justicia". Creo que es lícito remontarnos 41 años atrás, al Decreto 4 de la CG 32, "Nuestra Misión hoy: servicio de la fe y promoción de la justicia"s. Me parece legítimo comparar los énfasis de la CG 32 con los de la CG 36, a pesar de que entre ellas se encuentran las congregaciones generales 33, 34 y 35 , en cuyos textos encontramos énfasis complementarios, que profundizan en lo declarado por la CG 32 . También se observan énfasis discretamente diversos.

La comparación se justifica porque la CG 32 es la primera que creyó necesario y oportuno reformular, actualizándola, la misión de la Compañía de Jesús, desde $1550^{6}$. Las congregaciones 33,34 y 35 reformularon algunas declaraciones de la CG 32. En ese sentido, la CG 36 contiene la última reformulación de la misión.

\section{Una primera cala: algunos énfasis verbales diferentes}

La lectura del Decreto 4 de la CG 32, que se hizo famoso, y del Decreto 1 de la CG 36 pone de manifiesto algunos énfasis diferentes. Lo mismo se puede decir respecto al Decreto 2 de aquella congregación, sobre la identidad del jesuita ("Jesuitas hoy"). Este decreto afirma de manera inequívoca y con más fuerza que el Decreto 4 que ser compañero de Jesús significa "comprometerse bajo el estandarte de la cruz en la lucha crucial de nuestro tiempo, la lucha por la fe y la lucha por la justicia que la misma fe exige"7. La inserción de la cruz como estandarte corresponde plenamente con la formulación de la misión de la Compañía como "lucha" y no solo como "promoción".

La primera aproximación, quizás superficial, pero significativa, a las diferencias en los énfasis, es comparar las veces que las congregaciones 32 y 36 mencionan las palabras "justicia", o injusticia, y "reconciliación". El Decreto 4 de la CG 32 menciona "justicia" al menos 42 veces, en un texto conformado por 81 números. "Reconciliación" se menciona en cinco ocasiones. Además, cuatro

4. Los textos citados están tomados de la versión digital española, difundida el 7 de enero de 2017.

5. Congregación General XXXII de la Compañía de Jesús, 2 de diciembre 1974 - 7 de marzo 1975, pp. 69-100 (Madrid: Razón y Fe). Las mayúsculas del título son del texto español aprobado.

6. Año de la aprobación del texto reformado de la así llamada "Fórmula del Instituto de la Compañía de Jesús", que contiene la bula de Julio III, que modifica la bula de 1540 de Pablo III, con la aprobación de la Compañía de Jesús y su modo de ser fundamental como nueva orden religiosa.

7. Véase el libro citado en la nota 4, Decreto 2, 2, p. 45. 
veces menciona "reino", referido a "la anticipación del Reino que está por venir" (n. 27). Por tanto, anticipación acontecida en esta tierra.

En cambio, el Decreto 1 de la CG 36, organizado en 40 números, menciona "justicia" en once ocasiones y "reconciliación" al menos diecinueve veces. Adicionalmente, "misericordia", muy relacionada con "reconciliación", aparece nueve veces. De esa manera, el conjunto semántico reconciliación-misericordia figura en veintiséis lugares. Asimismo, "paz" aparece seis veces y en una ocasión, unida a "integridad de la creación", e "injusticia" se asocia una vez con "desigualdad", presente también en la CG $32^{8}$. Finalmente, "reino" aparece en una ocasión, en la misma línea que la CG 32, es decir, como fruto de la acción responsable y agraciada de las personas o los grupos. En síntesis, el conjunto semántico más relacionado con "justicia", es decir, "desigualdad", "paz", "integridad de la creación" y "reino", aparece en diecinueve sitios.

Ahora bien, la lectura atenta de estos textos nos permite un nivel de comprensión más profundo. Las tres primeras veces, de cinco, que el Decreto 4 hace uso de la voz "reconciliación" desentraña teológicamente la exigencia absoluta de promocionar la justicia. Las tres menciones se encuentran en los primeros veintisiete números - "Introducción", "Sumario", "Nuestra Misión ayer y hoy" y "Nuevos desafíos". En el número 2, la CG 32 declara que la "exigencia absoluta" de promocionar "la justicia" se fundamenta en - o se deriva de - que ella "forma parte de la reconciliación de los hombres"9 y en que esa reconciliación interhumana es una exigencia de "la reconciliación de ellos mismos con Dios". Dicho de manera más sencilla, "promocionar la justicia" o "luchar por la justicia", tal como lo dice más fuertemente "Jesuitas hoy", es la misión de la Compañía de Jesús hoy, porque es claro que sin justicia social, personal, institucional y estructural, es imposible que brote, como fruto de un árbol fecundo, la reconciliación entre las personas.

Esto significa que no se puede invocar una auténtica reconciliación entre las personas y los grupos humanos sin luchar por instaurar sólidamente la justicia, en las relaciones humanas y las instituciones familiares, sociales, económicas y políticas. La meta última de la condición humana, que hay que intentar aproximar históricamente en un mundo desgarrado por múltiples enemistades, conflictos y guerras, es la reconciliación y la amistad. Pero sin relaciones personales, institucionales y estructurales justas, no es posible alcanzar esa meta. $\mathrm{Y}$ esto

8. "Las desigualdades y las injusticias no pueden ya ser percibidas como el resultado de una cierta fatalidad natural; se las reconoce, más bien, como obra del hombre y de su egoísmo" $(32,4,27)$.

9. Hoy diríamos "de la humanidad" o "de las mujeres y los hombres", para evitar el privilegio masculino en el lenguaje, algo que refleja la realidad histórica. La CG 32 tuvo lugar en 1975. 
es evidente, porque sin fraternidad, sin solidaridad, sin valoración y sin respeto mutuo, lo que se instaura no es una reconciliación, sino la enemistad conflictiva.

Más allá de la "Introducción" y del "Sumario", en la primera y segunda parte del Decreto 4, dedicadas a "Nuestra Misión ayer y hoy" y a "Nuevos desafíos" (24-38), encontramos otro momento, donde la CG 32 reflexiona teológicamente sobre la relación entre la reconciliación y la justicia. El punto de partida es una afirmación que recoge, con intensa sensibilidad, el drama de nuestra época - no olvidemos que la CG tiene lugar en $1975^{10}$-, "el hombre puede hoy día hacer el mundo más justo, pero no lo quiere de verdad"'l. Y continúa con pathos intenso:

Su nuevo señorío sobre el mundo y sobre él mismo sirve frecuentemente más, de hecho, para la explotación de los individuos y las colectividades y los pueblos que para un reparto equitativo de los recursos del planeta; desencadena más rupturas y divisiones que comunión y comunicación, más opresión y dominación que respeto de los derechos individuales y colectivos en una real fraternidad. Las desigualdades y las injusticias no pueden ya ser percibidas como el resultado de una cierta fatalidad natural; se las reconoce, más bien, como obra del hombre ${ }^{12}$ y de su egoísmo ${ }^{13}$.

Desde este hacerse cargo ${ }^{14}$ de la realidad, fruto de un análisis entrelazado con la fe, pesimista y denunciante a la vez, la CG 32 piensa necesario cargar con $^{15}$ esa realidad, apelando a una fundamentación teológica, un desarrollo intelectual de la fe. Así, manifiesta lo que cree ser la vinculación del anuncio del evangelio con la promoción de la justicia. Digo "lo que cree", porque esa convicción, básicamente ética, de que sin anuncio del evangelio no se llega a promover la justicia,

10. Después del triunfo de la revolución maoísta de China, de la guerra de Corea, de las revoluciones y guerras independentistas de África, del encontronazo de Estados Unidos con la Unión Soviética por los misiles en Cuba, de la construcción del muro de Berlín, del comienzo de la guerra civil de Colombia, de la instauración de la dictadura militar en Brasil, del triunfo de la revolución sandinista en Nicaragua y del apoyo estadounidense a la contrarrevolución y la guerra campesina, del golpe militar contra la democracia y la revolución en libertad de Chile, etc.

11. Véase el libro citado en la nota 4, p. 79.

12. Ver nota 8.

13. Ver el libro citado en la nota 4, p. 80.

14. Según Ellacuría, en la misma línea de Zubiri, "hacerse cargo de la realidad" significa, epistemológicamente, "enfrentarse con las cosas", es decir, "estar en la realidad de las cosas [...] a través de sus mediaciones materiales y activas". Ver I. Ellacuría, "Hacia una fundamentación del método teológico latinoamericano", ECA 322-323 (1975), 419ss.

15. "Cargar con la realidad [...] señala el fundamental carácter ético de la inteligencia". Ver ibidem. 
se les impone a los congregados desde la $\mathrm{fe}^{16}$. Se trata de una proposición de ética creyente, más aún cristiana, que afirma una mutua conexión entre la fe en Jesucristo y la promoción de la justicia. En esto consiste tanto su enraizamiento en la tradición cristiana ${ }^{17}$ como la profundidad de su carácter de auténtica renovación histórica. Veámoslo:

No hay, pues, promoción propiamente cristiana de la justicia integral, sin un anuncio de Jesucristo y del misterio de la reconciliación que él lleva a consumación: es, en efecto, Cristo quien abre la vía para esta liberación total y definitiva a la que el hombre aspira desde lo más profundo de sí mismo. Y, a la inversa, no hay verdadero anuncio de Cristo, ni verdadera proclamación de su Evangelio, sin un compromiso resuelto por la promoción de la justicia ${ }^{18}$.

La última mención de la reconciliación acontece cuando la CG 32 deja claro que las raíces de su postura se encuentran en la Fórmula del Instituto de la Compañía de Jesús de 1550. Allí se menciona que esta ha sido

fundada principalmente para emplearse toda en la defensa y dilatación de la santa fe católica, en ayudar a las almas en la vida y doctrina cristiana, predicando, leyendo públicamente ${ }^{19}$ y ejercitando los demás oficios de enseñar la palabra de Dios, dando los Ejercicios espirituales, instruyendo a los niños y a los ignorantes en la doctrina cristiana, oyendo las confesiones de los fieles y ministrándoles los demás sacramentos para espiritual consolación de las almas. Y también es instituida para pacificar a los desavenidos, para socorrer y servir con obras de caridad a los presos de las cárceles y a los enfermos de los hospitales, según que juzgáremos ser necesario para la gloria de Dios y para el bien universal.

Inmediatamente, la CG 32 añade: "Estas referencias a nuestros orígenes siguen siendo capitales para nosotros"20. "Pacificar a los desavenidos" es la fórmula utilizada para decir que la Compañía de Jesús ha sido fundada para la reconciliación, es decir, para evitar que los diversos y conflictivos intereses, sobre todo, entre personas poderosas del siglo XVI, pero no solo entre ellas, terminen en guerra o enemistad duradera y mutuamente hiriente. Sin embargo, en el texto "institucional" de los orígenes no existe la misma relación teológica

16. Comunicación personal con Luis Achaerandio, Miguel Elizondo ( $\dagger$ ), Javier Scheifler $(\dagger)$, Juan Alfaro $(\dagger)$ y otros.

17. Ver J. I. González Faus, Vicarios de Cristo. Los pobres en la teología y espiritualidad cristiana (Madrid: Trotta, 1991).

18. Ver libro citado en la nota 4 , p. 80.

19. Esto es, enseñando e interpretando la Sagrada Escritura públicamente, en particular, en las universidades.

20. Ver libro citado en la nota 4, p. 74. 
entre "pacificar" y las demás "obras de caridad", que entre "reconciliación" y "justicia" de la CG 32.

En el siglo XVI, la "pacificación" puede leerse como una "misión" que se encuentra en el mismo nivel que las demás "obras de caridad". En cambio, en la CG 32, la preeminencia de las obras de caridad ha sido desplazada, como misión, a la promoción de o a la lucha por la justicia. Este desplazamiento, que sociológica y filosóficamente se basa en el descubrimiento de la dimensión estructural de las relaciones humanas, se fundamenta teológicamente en la relación entre reconciliación y justicia, como ya la hemos caracterizado. Por eso, en última instancia, la Compañía se encarga ${ }^{21}$ prácticamente de la promoción de la fe $y$ la justicia como misión, puesto que la reconciliación no acontece realmente si no se promueve la justicia, luchando por ella ${ }^{22}$.

Por su lado, la CG 36 define la misión de la Compañía hoy como "reconciliación y justicia". Asimismo, la CG 32 concreta esa misión de dos maneras: como "servicio a la fe y promoción de la justicia" (D 4) y como "comprometerse bajo el estandarte de la cruz en la lucha crucial de nuestro tiempo, la lucha por la fe y la lucha por la justicia que la misma fe exige" (D 2) ${ }^{23}$. La segunda manera de definir la misión de "los jesuitas, pecadores y, sin embargo, llamados a ser compañeros de Jesús"24, recuerda que el servicio a la fe y la promoción de la justicia constituyen una lucha contra "el pecado del mundo" (Jn 1,29), es decir, contra la atmósfera del mundo, históricamente contaminada de pecado. Por eso, están señalados por la cruz, es decir, el mundo reacciona violentamente contra aquellos que luchan por la fe y la justicia. Muchas veces, esa reacción acaba en asesinato o ejecución injusta, igual que aconteció con Jesús de Nazaret, que murió ejecutado injustamente, por el cruel método romano de la crucifixión.

21. "Encargarse de la realidad [...] señala el carácter práxico de la inteligencia, que solo cumple con lo que es, incluso en su carácter de conocedora de la realidad y comprensora de su sentido, cuando toma a su cargo un hacer real". Ver I. Ellacuría, "Hacia una fundamentación...", o. c.

22. A la CG 32 no le fue fácil decidirse por esta formulación de la misión como "lucha por la justicia". Según un miembro de dicha congregación, para "los padres polacos [...] 'la lucha por la justicia' sonaba a eslogan marxista". Y continúa: "hay que notar que para nuestros compañeros polacos el término estructura iba irremediablemente vinculado con la opresora retórica del materialismo dialéctico. Es interesante darse cuenta de que el mismo Juan Pablo II evita usar el término estructura en sus documentos, hasta la publicación de la encíclica Sollicitudo rei socialis (1987), aunque usándola y explicando su sentido, entonces, con gran precisión, en los nn. 36-38". Ver A. Álvarez Bolado, “La Congregación General 32”, en G. La Bella (ed.), Pedro Arrupe, General de la Compañía de Jesús. Nuevas aportaciones a su biografia, pp. 274-275 y 299, nota 102 (Santander: Sal Terrae-Mensajero, 2007).

23. Ver el libro citado en la nota 4, p. 45.

24. CG 32, D 2, 1; ver libro citado en la nota 4, p. 45. 
A primera vista, pareciera que el Decreto 2 expresa con más fuerza las consecuencias de ese servicio que el Decreto 4. Un servicio vivido además como lucha. Hay que reconocer que el Decreto 2 ("Jesuitas hoy") tiene una fuerza expresiva mayor y más concisamente contundente que el Decreto 4. Pero en este más nos encontramos también con la misma convicción de que promover la justicia, como parte de la nueva manera de formular y vivir la misión fundacional de la Compañía de Jesús, significa vivir bajo la sombra de la cruz: "No trabajaremos en la promoción de la justicia sin que paguemos un precio" 25 . En efecto, 46 jesuitas han muerto violentamente, entre 1975 y $2007^{26}$. Posteriormente, el Secretariado para la Justicia Social de la Compañía de Jesús ha añadido cuatro jesuitas también asesinados. El último es Frans van der Lugt, holandés, que trabajaba en Siria ${ }^{27}$. Y aún se encuentra secuestrado Paolo Dall'Oglio, italiano, también en Siria.

\section{Actualización de la CG 32}

Entonces, ¿en qué difiere la CG 36 de la CG 32 ? Podemos responder de dos maneras. La primera intuitivamente, por medio de una mirada al mundo actual. Me parece evidente la conciencia de la agudización de los conflictos, tanto económicos y sociales como políticos. Las guerras se han agudizado, desde el 11 de septiembre, cuando se produjeron los atentados en New York y Washington: el bombardeo de Afganistán, en 2001, y la ocupación de Irak, en 2003, por los ejércitos estadounidense y británico; el subsiguiente estallido de las revoluciones árabes y de la guerra en Siria; los brutales bombardeos de Israel en la Franja de Gaza palestina; los eternos conflictos de Colombia y en parte de Centroamérica; y la violencia contra los emigrantes y los refugiados, en el mundo entero. Todo esto ha suscitado un enorme deseo de paz y reconciliación. De ahí a sentir que la lucha contra la violencia y a favor de la paz es una llamada de Dios a la Compañía no hay más que un paso. Y eso pasa por la reconciliación, o al menos, debe terminar en ella, para poder ser una paz permanente.

La segunda respuesta se refiere a cómo concibe la CG 36 la reconciliación y la justicia. Para ello, es necesario estudiar los textos principales. Comenzaremos por la reconciliación.

Si contemplamos la realidad con los ojos de la fe [...] advertimos que Dios actúa en el mundo. Reconocemos las huellas del trabajo de Dios, del gran ministerio de reconciliación que Dios ha consagrado en Cristo, y que se realiza en el Reino de justicia, paz e integridad de la creación (D 1, n. 3).

25. lbid., p. 87.

26. Promotio Iustitiae, n. 117.

27. G. La Bella (ed.), Pedro Arrupe, o. c., pp. 1059-1065.

Digitalizado por Biblioteca "P. Florentino Idoate, S.J."

Universidad Centroamericana "José Simeón Cañas" 
En este texto se observa cómo la CG 36 ve la acción de Dios en el mundo desde la contemplación creyente. La CG 32 procedió de la misma manera, pero además apoyaba su contemplación en el análisis económico, social y político de la realidad, que no separaba de su visión creyente. Los analistas eran compañeros llenos de fe, que se enfrentaban con la realidad con herramientas humanas, compartidas también por increyentes, agnósticos y ateos. Con la ayuda de esas herramientas analíticas, la CG 32 enfatizó los nuevos desafíos para la misión de la Compañía.

El primer desafío era anunciar el evangelio a la humanidad, que desconocía a Jesucristo. El segundo era la "mutación cultural y socio-estructural", debida a las nuevas posibilidades tecnológicas y a los nuevos descubrimientos humanos. El cambio ha implicado la desintegración de los "valores tradicionales" y los "símbolos familiares", lo cual genera "nuevas aspiraciones que tratan de articularse en proyectos, programas y realizaciones concretas", evidentemente también novedosas. Una de las formas de esa desintegración conduce al "secularismo" multiforme y multicultural, que se expresa en "ciertas falsas imágenes de Dios, que consagran y legitiman la permanencia de estructuras injustas" intolerables, o que "quitan responsabilidades propias" a las personas.

La CG 32 afirma que este descubrimiento procede de nuestra experiencia y de la de nuestros contemporáneos, una experiencia que nos hace sufrir. Naturalmente, esta situación impulsó la búsqueda de "un nuevo lenguaje y nuevos símbolos" que, más allá "de los ídolos destruidos", permitieran reencontrar al "Dios verdadero [...] que, en Jesucristo, ha escogido tomar parte en la aventura humana" y comprometerse "irrevocablemente" con "su destino". Finalmente, la CG 32 menciona el rechazo de "estructuras de evangelización percibidas como ligadas a un orden social repudiado", y más en general, "la crisis de las instituciones y mediaciones" y la falta de percepción, por "quienes nos rodean", de "la calidad verdaderamente significativa de nuestros compromisos religiosos, sacerdotales y apostólicos".

El tercer desafío, ya mencionado, es la dramática constatación de que la humanidad "puede hoy día hacer el mundo más justo, pero no lo quiere de verdad"28. Pues bien, estos tres desafíos son el resultado de un profundo análisis social y antropológico-cultural con sensibilidad ético-filosófica, que precede a la proposición teológica, que proviene de la visión de fe.

A mi juicio, la metodología adoptada por esa congregación, que consistía en confrontar el análisis de las ciencias sociales y los postulados éticos con la propuesta teológica, explica, en parte, que sus decretos 2 y 4 hayan impresionado tan profundamente, en no pocos ambientes donde trabajaban los jesuitas, en

28. Ver libro citado en la nota 4 , pp. 77-80. 
la década de 1970. En concreto, Álvarez Bolado, uno de los miembros de esa congregación, afirma que

seguramente no ha habido ningún otro texto [Decreto 4] en cuyo contenido y formulación la Congregación haya participado tan dialéctica y activamente. Este decreto, que pasa a ser el más característico de la Congregación y el más expresivo del giro, es realmente un texto que la Congregación entera laboriosamente ha alumbrado ${ }^{29}$.

El giro del que habla Álvarez Bolado expresa el cambio crucial de perspectiva de la CG 32. Sin embargo, ese cambio fue anticipado por la CG 31, que coincide con el final del concilio Vaticano II. Previendo la necesidad de caminar en la estela conciliar, se abrió, también en el Decreto 4, e introdujo novedades en cosas hasta entonces tenidas por "sustanciales".

En definitiva, los dos decretos, el 2 y el 4, tienen el mismo valor, precisamente, porque el cuarto borrador, propuesto por el jesuita filipino Horacio de la Costa ${ }^{30}$, encontró inmediatamente un gran consenso. Probablemente, y en parte por su brevedad, contundencia y coherencia, formula con espíritu intrépido e inspirado (élan) la identidad del jesuita hoy, como la conjunción de los deseos expresados antes de la congregación, de la realidad, de las instrucciones de Pablo VI y de "la inspiración originaria de la Compañía"3i.

En un texto de importancia fundamental, la CG 36 declara que el "ministerio de reconciliación que Dios ha comenzado en Cristo [...] se realiza en el Reino de justicia, paz e integridad de la creación" (D 1, n. 3). Esta declaración expresa la convicción que animó a la CG 32: la realización del ministerio (diakonía) de la reconciliación. La creación de la paz tiene lugar en ese servicio que entraña la lucha por la justicia. Sin ese servicio, no hay posibilidad real para la reconciliación y la paz. De esta forma, este texto fundamental hermana las congregaciones 36 y 32 .

En consecuencia, el siguiente texto, referido a la reconciliación, debería, lógicamente, preceder al anterior.

En último término, pedimos con insistencia la gracia de saber cómo podemos tomar parte en el gran ministerio de reconciliación, sabiendo que, como nos recuerda el Papa Francisco, nuestra respuesta quedará siempre incompleta (D 1, n. 6).

La CG 36 parte de la convicción de que el ministerio -la diaconía, el servicio $^{32}$ - de la reconciliación se realiza en el reino de justicia, paz e integridad

29. A. Álvarez Bolado, "La Congregación General 32”, o. c., p. 333.

30. Ibidem, nota 171 .

31. Ibid., pp. 328-329.

32. El texto original de Pablo dice que Dios nos dio "ten diakonían tes katallagés" (2 Cor 5,18). Diakonía significa servicio, originalmente. 
de la creación, es decir, sabe que luchando por la justicia, la paz y la integración de la creación se está en camino de ese reino, anticipado también en la tierra.

La reconciliación implica una llamada a la conversión profunda de cada jesuita y de todos juntos. "La reconciliación con Dios es primero, y sobre todo, una llamada a la profunda conversión de cada jesuita y de todos juntos" $(1,17)$. La CG 35, en el Decreto 3 sobre la misión, termina diciendo que "la comunidad de la Compañía no es solo para la misión, ella misma es misión" $(3,41)$. La comunidad es "misión" por la calidad cristiana del trabajo al cual son enviados sus integrantes. Pero también por su estilo de vida, por la amistad y la alegría que suscita la convivencia, por la austeridad del modo de vivir, manifiesta en el desapego a los valores mundanos, por la apertura y la cercanía a los pobres. En una palabra, por constituir un testimonio. De los antiguos cristianos se decía, según Tertuliano: "Miren cómo se aman". Naturalmente, ese era un testimonio de cuán en serio habían tomado la palabra de Jesús: "Les doy un mandamiento nuevo, que se amen unos a otros como yo los he amado" (Jn 13,34). Esto supone una conversión permanente.

Es evidente que para vivir la lucha por la fe y la lucha por la justicia, que la misma fe exige, es necesaria la conversión de los jesuitas, una conversión personal, de sus costumbres y de los hábitos de su corazón ${ }^{33}$. Asimismo, la comunidad solo puede ser a la vez misión, es decir, envío apostólico al mundo, si se convierte igualmente. Por eso, el texto que comentamos descubre una de las principales metas de la CG 36: la vinculación profunda, más aún la unión, de vida y misión. No podemos predicar creíblemente la necesidad de austeridad, para contribuir a la vida de los pobres y a la disminución de la desigualdad en el mundo, si nosotros no vivimos austeramente, en nuestras comunidades. Y si nuestras casas no están abiertas, ¿cómo podemos llegar a ser testimonio de vida de comunidad? Por esa razón, la congregación declara: "En nuestras comunidades y ministerios escuchamos la llamada a redescubrir la hospitalidad para con los extranjeros, los jóvenes, los pobres y los que padecen persecución. El mismo Cristo es maestro de esta hospitalidad" $(1,16)$.

En este contexto de conversión, la congregación se pregunta "por qué los Ejercicios no nos cambian tan profundamente como podríamos esperar" ${ }^{34}$ (1, 18). Y afirma que "está seriamente convencida de que Dios está llamando a la Compañía en su conjunto a una renovación espiritual". De ahí que recuerde la frase que Ignacio de Loyola pidió al papa incluir en la Fórmula del instituto, que

33. Así escribía Tocqueville, en referencia a aquellos hábitos que, a su juicio y según su investigación de primera mano, hacían posible "la democracia en América".

34. C. Cabarrús escribió un artículo con esta pregunta, en 1989. Ver Diakonía 52 (1989), 415-425. Desde entonces, ha tratado este tema en repetidas ocasiones. 
cada jesuita "procure tener ante los ojos, mientras viva, primero a Dios" ${ }^{35}$. En este contexto recupera otra convicción de Ignacio:

los medios que nos unen directamente con Dios han de ser estimados y puestos en práctica más que nunca: los Ejercicios Espirituales, la oración diaria, la Eucaristía y el Sacramento de la Reconciliación, la dirección espiritual y el Examen" $(1,18)$.

Es aquí donde más se encuentran las voces reconciliación y misericordia. Así, el decreto recuerda y enfatiza que "en el corazón de la espiritualidad ignaciana se da un encuentro transformador con la Misericordia de Cristo". Se trata, pues, de una experiencia espiritual profunda.

La experiencia de la misericordia con la que Dios mira nuestras debilidades y nuestro pecado nos hace humildes y nos llena de gratitud ayudándonos a convertirnos en ministros de misericordia para todos ${ }^{36}$.

Esta experiencia es tanto personal como institucionalmente fundante. En realidad, los Ejercicios espirituales, la experiencia clave para ingresar en la Compañía de Jesús, comienzan con esa experiencia de misericordia. De ahí que la congregación agregue que esa experiencia "ha sido siempre fuente de aquella audacia que la Compañía ha portado siempre como marca, y que es nuestro deber preservar" $(1,19)$. Se alude, por supuesto, a una audacia apostólica, es decir, en la misión. Pero enseguida, subrayando la correlación entre vida y misión, cita de nuevo el discurso del papa Francisco: "Misericordia no significa algo abstracto, sino un estilo de vida, que consiste en gestos concretos más que en meras palabras" 37 .

Por eso, la congregación enfatiza: "Para nosotros jesuitas, la compasión es acción y una acción discernida en común". Entra aquí el fuerte acento que las congregaciones posteriores al Vaticano II dan a la experiencia del discernimiento, desde la CG 31, que aún usaba la fórmula "discreción de espíritus" 38 . El texto continúa de una forma más incisiva, que recuerda a los obispos latinoamericanos en Puebla, en $1979^{39}$.

Más aún, sabemos bien que no existe auténtica familiaridad con Dios si no permitimos que tanto la compasión como la acción nos lleven al encuentro

35. Fórmula del Instituto (1550), 1.

36. Alocución del papa Francisco a la CG 36, 24 de octubre de 2016.

37. Ibidem.

38. Ver el índice analítico de las congregaciones 31 (discreción de espíritus), 32, 33, 34 y 35 (discernimiento, discernir).

39. III Conferencia General del Episcopado Latinoamericano, Puebla. Comunión y Participación, nn. 31-39 (Madrid: BAC, 1982). 
con Cristo que se revela en los rostros doloridos y vulnerables de la gente, y, naturalmente, en el sufrimiento de la creación ${ }^{40}$.

Los textos citados son clave para entender la íntima relación entre la reconciliación, fundamentada en la compasión y en la acción, y la lucha por la justicia, cuya alma consiste en cargar con una actitud ética nueva a quienes hoy constituyen los "rostros doloridos y vulnerables" de Jesús, crucificado una vez más en sus vidas, y en encargarse de ellos con una praxis consecuente.

De los dos textos citados del papa Francisco, el último está relacionado con otros dos del mismo discurso.

Siempre se puede dar un paso más en el dejarnos conmover por el Señor nuestro puesto en cruz, por Él en persona y por Él presente en tantos hermanos nuestros que sufren - ¡la gran mayoría de la humanidad! El P. Arrupe decía que allí donde hay un dolor, allí está la Compañía [o al menos, tendría que estar].

Y más adelante, en el mismo discurso:

El Señor que nos mira con misericordia y nos elige, nos envía a hacer llegar, con toda su eficacia, esa misma misericordia a los más pobres, a los pecadores, a los sobrantes y crucificados del mundo actual que sufren la injusticia y la violencia.

El papa no habla únicamente de la compasión personal, que se ejerce, por ejemplo, visitando frecuentemente a una persona enferma, terriblemente adolorida y desgastada, en su casa o en el hospital, sino que habla también de la compasión, por decirlo así, estructural, que consiste en denunciar las estructuras y en tratar de cambiarlas, ayudando a encontrar otro sistema económico que no mate ${ }^{41}$.

Estas ideas se encuentran en el diálogo con los jesuitas congregados, que siguió al discurso en el aula de la congregación.

Pensemos en Medio Oriente, en África: allí se da una situación de continuas guerras. Guerras que se derivan de toda una historia de colonización y explotación. Es cierto que hay países que tienen su independencia, pero muchas veces el país que les dio la independencia se reservó el subsuelo para sí. África sigue siendo un objetivo de la explotación por las riquezas que tiene [...] A África siempre se le mira desde la óptica de la explotación.

En otro momento, no citándolo, pero refiriéndose, sin duda, a Zygmunt Baumann, recién fallecido, y a su teoría del "mundo líquido" actual, Francisco dijo lo siguiente:

40. Mateo 25,31-46.

41. Ver Evangelii gaudium 53. 
Destaco, también, el problema de la liquidez, que puede anular lo concreto [...] La liquidez de la economía, la liquidez del trabajo: todo esto provoca desocupación [...] Existe el derecho de recuperar la dimensión concreta del trabajo. En Italia el 40 por ciento de los jóvenes de 25 años para abajo, están desocupados; en España, el 50 por ciento, en Croacia el 47 por ciento. Es una señal de alarma que nuestra liquidez crea desocupación.

El primer decreto de la CG 36 habla con mayor amplitud de reconciliación, en la sección titulada "En misión con Cristo reconciliador" (21-30).

Con frecuencia y con fuerza fue emergiendo la llamada a participar en la obra de reconciliación que Dios está realizando en nuestro mundo herido. Lo que la CG 35 había localizado como las tres dimensiones de esta labor de reconciliación, es decir, la reconciliación con Dios, la de unos con otros y la de los seres humanos con la creación, ha adquirido nueva urgencia. Esta reconciliación es siempre obra de la justicia; una justicia discernida y formulada por las comunidades y contextos locales. En el centro de la obra de la reconciliación de Dios se encuentra la cruz de Cristo y también nuestra participación en ella. Esta misión puede conducir al conflicto y a la muerte, como lo hemos testimoniado en la vida de muchos de nuestros hermanos. Aunque hablamos de tres formas de reconciliación, en realidad, las tres son una única acción de Dios, interrelacionada e inseparable $(1,21)$.

El primer párrafo destaca las tres dimensiones de la obra de reconciliación que Dios realiza en este mundo herido: la reconciliación con Dios, entre los seres humanos y de estos con la creación. Al hablar de la misión "con Cristo", la congregación parece poner el acento en que la misión ha de llevarse a cabo en compañía del Señor "resucitado". Sin embargo, el texto citado de Pablo (2 Cor 5,18-21) termina recordando que el Cristo resucitado es el mismo Jesús crucificado, "a quien Dios hizo pecado", aunque nunca se casót ${ }^{42}$ con el pecado, es decir, nunca aceptó tener en sí mismo la experiencia personal ${ }^{43}$ de pecador. Al contrario, él es "el que quita el pecado del mundo" (Jn 1,29).

Así, pues, la Compañía ha de llevar a cabo su misión en compañía del Señor resucitado, que es el mismo Señor Jesús crucificado. Precisamente, por eso, subraya con fuerza la relación entre misión y cruz: "En el centro de la obra de la reconciliación de Dios se encuentra la cruz de Cristo y también nuestra participación en ella". Esto vincula la misión de la Compañía con la muerte de los jesuitas que, asesinados a causa del conflicto provocado por el cumplimiento de dicha misión, han testimoniado su coherencia con sus vidas hasta el final, es decir, han

42. Literalmente: "aunque nunca conoció pecado". Bien sabemos las connotaciones bíblicas de "conocer", una voz simbólica de la unión sexual.

43. Ver S. Vidal, Las cartas auténticas de Pablo, p. 410, nota 81 (Bilbao: Mensajero, 2012). 
sido mártires. En la tumba de los mártires jesuitas en la UCA de El Salvador, se encuentra inscrita la convicción de la CG 32: "No trabajaremos en la promoción de la justicia sin que paguemos un precio" $(4,46)$.

En correspondencia con el famoso texto profético de Isaías $(32,17)$, "la paz será obra de la justicia", este texto afirma que "esta reconciliación es siempre obra de la justicia", y añade que se trata de "una justicia discernida y formulada por las comunidades y contextos locales", es decir, una justicia que no viene de arriba y se agota en textos legales o incluso constitucionales, sino que viene desde abajo y florece y fructifica en la medida en que las comunidades y sus líderes piensan por sí mismos, proponen y actúan públicamente.

En la llamada a la reconciliación con Dios se intuye el impacto causado en los padres congregados por la intensidad con la que el papa se refirió a la experiencia de "consuelo" de Dios y a la "alegría" que procede de él en la misión.

$\mathrm{Al}$ acogerla, la reconciliación con Dios nos enraíza en la gratitud y nos abre a la alegría. El Papa Francisco escribe: "La alegría del Evangelio llena el corazón y la vida entera de los que se encuentran con Jesús [...] Con Jesucristo siempre nace y renace la alegría"44. Anunciar y compartir el Evangelio sigue siendo para la Compañía la razón de su existencia y su misión: que Jesucristo sea conocido, que sea correspondido en su amor, y que el amor de Cristo sea fuente de vida para todos. Él sigue siendo la fuente de gozo y esperanza que ofrecemos a los demás. Por eso, la Compañía debe responder de manera más decisiva a la llamada de la Iglesia a una nueva evangelización, poniendo un énfasis especial en el servicio a y con los jóvenes y las familias $(1,22)$.

La misión de los jesuitas consiste en ayudar al pueblo a vivir en esperanza, superando la potencia del mal en el mundo, y a distinguir la alegría auténtica del evangelio de los "fuegos fatuos [...] al alcance de la mano en cualquier comercio". El comienzo de la Segunda carta a los corintios da cuenta de ese consuelo cotidiano, en medio de los sufrimientos. También lo hacen, tal vez con más claridad, el evangelio de las bienaventuranzas y el llamado de Jesús a no vivir acongojados o angustiados por las preocupaciones de la vida, y a vivir, en cambio, "buscando el reino de Dios y su justicia"æ.

El decreto confirma que para la reconciliación con Dios, podemos ofrecer algo muy nuestro, los instrumentos de nuestra espiritualidad ignaciana, los cuales, evidentemente, son ya profundamente eclesiales ${ }^{46}$. Luego, señala la complejidad de los contextos, donde se desarrolla la misión: el desafío de la secularización, del diálogo interreligioso, del abandono de la Iglesia y de ayudar

44. Evangelii gaudium 1.

45. 2 Cor 1,3.11; Mt 5,1-12; Lc 6,20-26; y Mt 6,31-33.

46. CG 36, 1, 23.

Digitalizado por Biblioteca "P. Florentino Idoate, S.J."

Universidad Centroamericana "José Simeón Cañas" 
a profundizar en el evangelio, acompañando al pueblo, desde las más diversas tradiciones culturales, con el trabajo teológico y exegético ${ }^{47}$.

La segunda llamada a la reconciliación de la humanidad no necesita comentario, porque está en continuidad con el pathos de la CG 32 y de la adición introducida por la CG 33, en la línea de Puebla $1979^{48}$.

A lo largo de nuestra preparación para esta Congregación, como cuerpo universal con una misión universal ${ }^{49}$, hemos escuchado relatos sobre las escandalosas formas de sufrimiento e injusticia que padecen millones de hermanos y hermanas nuestros. Al reflexionar sobre todo ello escuchamos a Cristo que nos convoca de nuevo a realizar un servicio de justicia y de paz, sirviendo a los pobres y excluidos y ayudando a construir la paz [...] Entre las diversas formas de sufrimiento, tres aparecen con mayor consistencia:

a) Los desplazamientos de población (refugiados, migrantes y desplazados internos [...] nuestra fe invita a la Compañía a promover [...] una más generosa cultura de la hospitalidad [...] promover una articulación internacional de nuestro servicio a los migrantes y refugiados, encontrando formas de colaboración con el SJR ${ }^{50}$.

b) Las injusticias y desigualdades que viven los pueblos marginados: Junto a un enorme crecimiento de la riqueza y el poder en el mundo, se da un enorme y continuo crecimiento de la desigualdad [...] Jóvenes, personas vulnerables [...] pueblos y comunidades indígenas como los dalits y tribales [...] son las mujeres las que viven esta injusticia de modo particular [...] llamados a apoyar a estas comunidades en sus luchas, reconociendo que tenemos mucho que aprender de sus valores y su valentía. La defensa y promoción de los derechos humanos y de una ecología integral constituyen un horizonte ético que compartimos con muchas personas de buena voluntad [...].

c) El fundamentalismo, la intolerancia y los conflictos étnico-religiosopolíticos, son fuente de violencia [...] creciente nivel de conflicto y polarización tanto más escandalosa [...] cuanto [justificada] en convic-

47. CG 36, 1, 24.

48. Aunque la conferencia del episcopado latinoamericano no está citada en el número 105 de la CG 33, donde se hace la opción preferencial por los pobres, puede afirmarse que dicha conferencia influyó mucho, sobre todo, a través de los jesuitas latinoamericanos. Las fuentes citadas por la CG 33 son Evangelica testificatio $(17,18)$, de Pablo VI; Laborem excercens (8) y Dives in misericordia (3), de Juan Pablo II; y Arraigados en la caridad (61, AR XVIII, 1981, 462), de Pedro Arrupe.

49. CG 35, 2, 20.

50. El Servicio Jesuita para Refugiados, fundado por el P. Pedro Arrupe, en 1981, a raíz de la "gente de las balsas", que huía de Vietnam. 
ciones religiosas deformadas [...] los jesuitas, junto con todos aquellos que buscan el bien común, están llamados a contribuir, desde su tradición religioso-espiritual, a la construcción de la paz [...] local y global (1, 25-28).

Los dos siguientes números, que figuran bajo el acápite "3. Llamada: la reconciliación con la creación", constituyen, a mi juicio, los dos textos más importantes del Decreto 1.

El Papa Francisco ha subrayado la conexión fundamental que existe entre la crisis ambiental y la crisis social que vivimos actualmente ${ }^{51}$. La pobreza, la exclusión social y la marginación tienen conexión con la degradación del ambiente. No se trata de crisis independientes, sino de una única crisis que es síntoma de algo mucho más profundo: el modo equivocado como están organizadas nuestras sociedades y nuestras economías. El sistema económico actual, con su enfoque depredador descarta tanto los recursos naturales como las personas ${ }^{52}$. Por esta razón el Papa Francisco insiste que la única solución adecuada es una solución radical. La orientación del desarrollo debe ser cambiada para que este sea sostenible. Los jesuitas estamos llamados a prestar ayuda en la sanación de un mundo herido ${ }^{53}$, promoviendo una nueva forma de producción y de consumo que coloque la creación en el centro $(1,29)$.

Así, pues, la congregación asume algunos de los aportes fundamentales de la enseñanza social del papa Francisco e invita a los jesuitas a trabajar eficazmente en la línea de la lucha por la justicia. Cabe recordar que antes, la congregación ha subrayado que "la reconciliación es obra de la justicia", al igual que la paz es fruto de la reconciliación por la justicia (Is 32,17). En el diálogo con los congregados, el papa insistió en que la 'Laudato Si' no es una 'encíclica verde'. Es una encíclica social. Es evidente que los que sufren las consecuencias son los más pobres, los que son descartados". Antes había dicho que "es evidente que el mundo está sufriendo, no solo por el recalentamiento sino por el mal uso de las cosas y porque la naturaleza es maltratada". Por tanto, "Es necesario trabajar mucho la parte social de la encíclica, porque los teólogos que trabajaron en ella se preocuparon mucho en ver cuánta repercusión social tienen los hechos ecológicos. Ayuda mucho que se la vea como una encíclica social".

En el siguiente número (30), es evidente el énfasis de la congregación en la unión de vida y misión, vida real y misión real.

51. Laudato $\mathrm{Si}^{\prime} 139$.

52. "Por una economía global justa: construir sociedades sostenibles e inclusivas", Promotio Iustitiae 121.

53. "Sanar un mundo herido", Promotio Iustitiae 106. 
El desafío polifacético de nuestro hogar común exige de la Compañía una respuesta también polifacética. Comencemos por cambiar nuestro estilo de vida personal y comunitario, adoptando un proceder que sea coherente con nuestro deseo de reconciliación con la creación. Tenemos que acompañar y permanecer cercanos a los más vulnerables. Nuestros teólogos, filósofos y otros intelectuales y expertos deben contribuir a hacer un análisis riguroso de las raíces y soluciones de la crisis. El compromiso de la Compañía con regiones como la Amazonia y la Cuenca del Congo, esenciales reservas ambientales para el futuro de la humanidad, debe ser apoyado. Hemos de gestionar nuestras inversiones económicas de modo responsable. Y no podemos olvidar celebrar la creación, dando gracias por "tanto bien recibido"s4 $(1,30)$.

La unión inseparable y profunda de vida y misión tiene prioridad. Es la meta de nuestra conversión. ¿Cómo trabajar por los pobres, sin "caminar paciente y humildemente con los pobres"? Debemos aprender

en qué podemos ayudarles después de haber aceptado primero recibir de ellos. Sin este paciente hacer camino con ellos, la acción por los pobres y los oprimidos estaría en contradicción con nuestras intenciones y les impediría hacerse escuchar en sus aspiraciones y darse ellos a sí mismos los instrumentos para tomar efectivamente a su cargo su destino personal y colectivo" (CG 32, 50).

Así, pues, las congregaciones 36 y 32 coinciden en este punto. Este párrafo de la CG 32 causó un gran impacto, en su momento, porque penetraba en el núcleo del sistema capitalista salvaje ${ }^{55}$-el neoliberalismo del final de la historia y del

54. Ejercicios espirituales 233.

55. "De acuerdo con la crítica de Hollenbach, tanto el Compendio [de Doctrina Social de la Iglesia] como Caritas in veritate, de Benedicto XVI, requieren una revisión a la luz de la intuición formulada por Paul Ricoeur, de que la vida buena siempre se vive 'con y para otros en instituciones justas' [...] En muchos contextos la opresión y unas instituciones injustas impiden a la gente vivir una vida digna". Ver J. Verstraeten, "Nueva visión de la economía, iuna cuestión de amor o de justicia? El asunto del 'Compendio de Doctrina Social de la Iglesia' y la Encíclica "Caritas in veritate", Concilium 343 (2011), 783. La crítica aludida se encuentra en D. Hollenbach, "Caritas in veritate. The meaning of love and urgent challenges of justice", Journal of Catholic Social Thought 8:1 (2011), 171-182. Mario Blacutt Mendoza, filósofo y economista boliviano, afirma que "Una clase nueva de economía de libre mercado nace alrededor del globo y sus consecuencias económicas y sociales podrían estar generando una serie de resultados negativos. Se advierte que el libre mercado ha ido creciendo hasta convertirse en un tobogán. Estamos viendo y veremos los aumentos masivos en la pobreza, en el crimen y en el desempleo, especialmente en el Tercer Mundo, que carece de los sistemas políticos y legales con que cuentan los Estados avanzados. A esta economía descontrolada y con consecuencias 
Consenso de Washington de la década de 1990. Solo el crecimiento personal y grupal, imaginativo y solidario, profundamente humano, de muchas personas pobres y de sus compañeros, puede hacer avanzar hacia una alternativa viable.

Ya avanzada la segunda década del siglo XXI, la CG 36 unifica acertadamente la lucha por la justicia y la paz, que de ella puede $\operatorname{brotar}^{56}$. Conviene insistir.

Comencemos por cambiar nuestro estilo de vida personal y comunitario, adoptando un proceder que sea coherente con nuestro deseo de reconciliación con la creación. Tenemos que acompañar y permanecer cercanos a los más vulnerables $(1,30)$.

Aquí se alude casi por primera vez a la crisis que, desde 2007-2008, ha sumergido al mundo en penalidades tan mortales como las de la década de 1930, causadas por la gran depresión del capitalismo mundial. Esta es también la primera vez que se menciona explícitamente la necesidad del análisis. Las consecuencias ecológicas son tan terribles como las meramente humanas.

El compromiso de la congregación con la Amazonia y la Cuenca del Congo es bastante novedoso. La Amazonia es el mayor depósito de agua del planeta, pero la codicia de los grandes plantadores y las compañías mineras devasta esas tierras, sin que los gobiernos, incluido el de Lula, marcado por un fuerte sentido de lo social, hayan podido impedirlo. Tal vez ni siquiera lo han intentado. Por otro lado, las grandes potencias y las multinacionales intentan sobornar y enfrentar a las etnias africanas para apoderarse del coltan, un mineral básico para la electrónica, y de los diamantes, entre otros minerales estratégicos. La importancia de recordar la responsabilidad de las obras, a la hora de invertir fondos y gestionarlos, es evidente.

El llamado a celebrar la creación también es novedoso, pues el espíritu de fiesta, por lo general, no suele ser algo que los jesuitas promovamos en nuestra actividad.

extremadamente negativas para los países que no pueden oponérsele, se le llama capitalismo salvaje"; en WEB, "Capitalismo salvaje", consultado el 26/01/2017. En esa misma línea, Bernardo Kliksberg, en la conferencia organizada por la Federación de Cooperativas de Paraguay, declaró que "El capitalismo salvaje crea monopolios y controla el mercado, que operando a través de las multinacionales genera una enorme desigualdad social [...] El capitalismo salvaje pretende eliminar totalmente al Estado de su tarea de contralor, regulador, para adueñarse, a placer, del mercado [...] Esta práctica promovida por economistas ortodoxos es la que está generando cada vez más pobreza en el mundo"; ibidem, consultado el 26/01/2017.

56. CG 34, 4, 50. 


\section{La renovación de la vida apostólica}

La renovación de la vida apostólica de la Compañía de Jesús es el último tema del Decreto 1. La congregación recuerda que "construir puentes para promover la paz" ${ }^{\text {"77 }}$ forma parte de la misión de la Compañía. Probablemente impactados por la persistencia, e incluso el agravamiento, de los conflictos violentos en el Oriente Medio, África, América, en particular, en el llamado "triángulo norte" de Centroamérica y en México, y en el centro de Europa, los congregados llaman a "alcanzar una comprensión más profunda del misterio del mal en el mundo y del poder transformador de la misericordiosa mirada de Dios que trabaja por hacer de la humanidad una familia reconciliada y en paz".

La siguiente llamada, cuya realización depende de la conversión auténtica y profunda, tiene una gran fuerza.

Con Cristo estamos llamados a estar cercanos a la humanidad crucificada. Junto a los pobres podemos contribuir a crear una familia humana a través de la lucha por la justicia. Quienes tienen cubiertas todas las necesidades y viven lejos de la pobreza también necesitan el mensaje de esperanza y reconciliación que los libera del miedo a los migrantes y los refugiados, a los excluidos y a los que son diferentes, para abrirse a la hospitalidad y a la paz con los enemigos $(1,31)$.

La congregación aplica, una vez más, el "contribuir a crear una familia humana, a través de la lucha por la justicia", a obras apostólicas específicas.

Nuestras obras educativas a todos los niveles y nuestros centros de comunicación e investigación social, tienen que ser una ayuda para la formación de hombres y mujeres comprometidos con la reconciliación, que sean capaces de superar los obstáculos que a ella se oponen $(1,34)$.

No es fácil exagerar la importancia, incluso la trascendencia, de los colaboradores en la renovación apostólica eficaz.

La colaboración con otros es la única manera que tiene la Compañía de realizar la misión [...] Esta asociación en la misión incluye a aquellos que profesan como nosotros la fe cristiana, a los que pertenecen a religiones diferentes y a hombres y mujeres de buena voluntad que, como nosotros, desean colaborar en la obra reconciliadora de Cristo $(1,36)$.

La coherencia con el reconocimiento de la amplitud y la profundidad de las diversas motivaciones e identidades de los colaboradores con la misión de la Compañía, pedía concluir, más o menos, de la siguiente manera: “... que como

57. Fórmula del Instituto (1550), 1: "Y también manifiéstese preparado para reconciliar a los desavenidos". Esto se encuentra también en la CG 35, que habla de "tender puentes". 
nosotros, desean colaborar en la obra reconciliadora de Cristo o en la obra de crear y facilitar nuevas relaciones humanizadoras ${ }^{58}$, que vayan conduciendo hacia la paz". De esa manera, habría mayor coherencia con la afirmación siguiente: "En todo lo que hacemos deseamos seguir al Papa Francisco [...] y así privilegiar las acciones que generan dinamismos nuevos en la sociedad"59.

La congregación sabe que esto no se podrá lograr en el mundo actual, si no es "por medio de redes [...] internacionales e intersectoriales, donde se refuerce nuestra identidad y se compartan recursos y compromisos hasta los niveles locales"60.

\section{La conclusión del Decreto 1}

El Decreto 1 recuerda cómo después de la experiencia de Venecia, en 15371538 , los nueve "amigos en el Señor" de Ignacio ${ }^{61}$, casi todos exalumnos de la Universidad de París, vivieron juntos, dedicados a la predicación del evangelio y a cuidar a los pobres y los enfermos, mientras aguardaban la posibilidad de navegar juntos a Tierra Santa. Al no conseguirlo, peregrinaron a Roma y decidieron, en una deliberación, vivir y ser admitidos en la Iglesia, como una nueva comunidad religiosa. Por tanto, se pusieron bajo la autoridad del Pablo III, que confirmó su carisma, en 1540. La congregación declara que ha experimentado "la gracia de ser confirmada, apoyada y enviada por el Papa Francisco", quien "ha subrayado que no podemos conformarnos con el statu quo de nuestros ministerios. Nos ha impulsado una vez más al magis, a 'ese plus' que llevó a Ignacio a evaluar su real incidencia en la vida de las personas"62 $(1,39)$.

Enseguida, concluye con la siguiente confesión de fe, que habla por sí misma.

Creemos que Dios continúa su obra de "reconciliar el mundo consigo en Cristo" ${ }^{\text {". }}$. Escuchemos la urgente llamada a unirnos al Señor en la atención a los más necesitados y a extender la misericordia de Dios allá donde la injusticia, el sufrimiento y la desesperación parecen desbaratar el plan divino. Pedimos el valor y la libertad de tener "la audacia de lo "improbable", en nuestra respuesta a la llamada de Dios "con la humildad de quien sabe que,

58. P. Trigo, Relaciones humanizadoras. Un imaginario alternativo (Santiago de Chile: Ediciones Universidad Alberto Hurtado, 2013). Especialmente, el capítulo VI.

59. CG 36, 1, 36 y 37.

60. CG 36, 1, 35.

61. Así los llama el mismo Ignacio, en una carta a Juan de Verdolay: "De París llegaron aquí mediado enero nueve amigos míos en el Señor". Ver J. Osuna, Amigos en el Señor. Unidos para la dispersión, p. 17 (Santander: Mensajero-Sal Terrae, 1998).

62. Alocución del papa Francisco a la CG 36, 24 de octubre de 2016. "Darle prioridad al tiempo es ocuparse de iniciar procesos más que de poseer espacios".

63. 2 Cor 5,19 . 
en este servicio en el que los seres humanos comprometemos toda nuestra energía, "todo depende de Dios"'64. Mirad, jeste es el tiempo favorable, este es el día de salvación!"

La insistencia de la CG 36 en la unidad de la vida y la misión confirma y actualiza los cuatro decretos fundamentales de la CG 32 -"Jesuitas hoy" (2), "Nuestra Misión hoy: servicio de la fe y la promoción de la justicia" (4), "La unión de los ánimos" (11) y "Pobreza" (12).

Antes de concluir, añado, con cierto dejo de humor, que respondería negativamente a la pregunta con la que empecé. Es decir, la CG 36, al enunciar la misión de la Compañía de Jesús hoy, no se desvía de lo que, audaz y novedosamente, enunciaron los padres congregados en la CG 32. Indudablemente, la respuesta a esa pregunta la dará cada compañero jesuita, en su corazón, y tal vez la comparte con otros. Con todo, dado que la congregación declara que "Esta reconciliación es siempre obra de la justicia" $(1,21)$, el decreto debiera haber sido titulado "Compañeros en una misión de reconciliación siempre por la justicia", en lugar de "Compañeros en una misión de reconciliación y justicia". Así se habría evitado pensar que la CG 36 propone una reconciliación que ya no enfatiza la necesidad de luchar por la justicia.

64. Homilía del P. Bruno Cadoré, O. P., en la misa de apertura de la CG 36. Notemos que en su literalidad, tradicional, el principio aquí propuesto, se suele formular más dialécticamente: "Hacer todo como si de nosotros dependiera y esperarlo como si todo dependiera de Dios". A veces, incluso se ha expresado así: "Hacer todo como si todo dependiera de Dios y esperarlo como si todo dependiera de nosotros". Ver G. Fessard, La dialéctica de los Ejercicios espirituales, de san Ignacio de Loyola (Santander: Mensajero-Sal Terrae, 2010). Los dos primeros tomos se publicaron en 1956, y el tercero, concebido como un epílogo, en 1985, ya muerto Fessard, en 1978.

65. 2 Cor 6,2 . 